here. They found that two of Negroni's isolates had the properties of mycoplasma (pleuropneumonia-like organism), but point out that their work does not preclude the possibility of both a mycoplasma and a virus being present. With the techniques being employed in our laboratory, neither agent was isolated from bone-marrow-cell suspensions of children with acute leukaemia.

\section{Summary}

Attempts were made to isolate viral agents from 19 bonemarrow-cell suspensions obtained from 17 children with acute leukaemia by means of four to six blind passages in humanembryonic-kidney cells. Unlike the positive findings reported by Negroni (1964) on similar material, we were unable to detect the presence of viral agents in any of the inoculated cultures or their blind passages.

\section{REFERENCES}

Ang, B., Jaross, L., and McAllister, R. M. (1962). Proc. Soc. exp. Biol. (N.Y.), 109, 467.

Benyesh-Melnick, M., Fernbach, D. J., and Lewis, R. T. (1963). f. nat. Cancer Inst., 31, 1311.

Rosenberg, H. S., and Watson, B. (1964). Proc. Soc. exp. Biol. (N.Y.), 117, 452.

Berg, R. B., and Rosenthal, M. S. (1961). Ibid., 106, 614.

Girardi, A. J., Slotnick, V. B., and Hilleman, M. R.'(1962). Ibid., 110,

Grist, N. R., and Fallon, R. J. (1964). Brit. med. F., 2, 1263.

Murphy, W. H., and Furtado, D. (1963). Univ. Mich. med. Bull., 29, 201.

Negroni, G. (1964). Brit. med. 7., 1, 927.

Rowe, W. P., Huebner, R. J., Gilmore, L. K., Parrott, R. H., and Ward, T. G. (1953). Proc. Soc. exp. Biol. (N.Y.), 84, 570.

\title{
Daily Variations in Sputum Volume in Chronic Bronchitis
}

\author{
THOMAS ASHCROFT,* M.B., CH.B.
}

Brit. med.7., 1965, 1, 288-290

The volume of sputum expectorated in the first hour after waking in the morning has been measured in field studies of chronic bronchitis (Fletcher, Elmes, Fairburn, and Wood, 1959 ; Elmes, Dutton, and Fletcher, 1959) and has been found to correlate well with subjective and objective indices of the subject's condition, but there are surprisingly few references in the literature on the total volume of sputum produced and the pattern of its expectoration during the day. The present study was undertaken to discover the relation of the first-hour volume to the total volume of sputum produced in 24 hours, and also the degree of variation in these volumes from day to day. Since, in epidemiological work, it would be more convenient to collect sputum over the first half-hour of the day rather than the first hour, measurements of the volume produced in this time (half-hour vol.) were also made. In addition, measurements were later made on 10 subjects to establish their pattern of sputum-production from hour to hour throughout the day.

\section{Methods}

Forty-eight male patients took part in the main investigation. All were in hospital recovering from acute exacerbations of chronic bronchitis, and all but eight also had either simple or complicated coal-workers' pneumoconiosis. One subject, without pneumoconiosis, had a bronchial carcinoma in addition to chronic bronchitis. The subjects were all ambulant, and their average age was 59.5, with a range of 45-74. Twenty-nine patients took part in the one-hour series and 31 in the half-hour series. Twelve took part in both series. Patients were selected who were free from obvious infection and were producing mostly mucoid sputum. Each man took part for seven consecutive days, except for two patients in the half-hour series who were discharged after four and six days respectively and three others who took part for eight days.

One-hour and Half-hour Series.-In the one-hour series patients were awakened at 5 a.m. and all sputum brought up in the first hour was collected in a standard universal container.

\footnotetext{
* Medical Research Council, Pneumoconiosis Research Unit, Llandough Hospital, Penarth, Glamorgan. Present address: University of Newcastle upon Tyne, Department of Pathology, Royal Victoria Infirmary, Newcastle upon Tyne 1.
}

At 6 a.m. this container was exchanged for a fresh one, in which all further sputum until 5 a.m. the following morning was collected. If the patient's sputum volume was large, extra containers were issued during the day as required and the sum of their contents was taken. In the half-hour series, containers were exchanged at 5.30 a.m. Sputum volume was measured, after destroying froth as far as possible by adding a few drops of capryl alcohol or silicon defrothing agent, by a specially made rule graduated at $2.5,5,10,15,20$, and $25 \mathrm{ml}$. The height of the sputum column to the bottom of any remaining froth was read off on the scale, reading the first mark below, and recorded as the middle of the range between this mark and the next above. The rule was calibrated by measuring the height of known volumes of water in 10 randomly selected containers, including the thickness of the bottom of the container in the measurement. The mean height at each volume was then engraved on the scale. The height of a given volume of water varies surprisingly little between containers in spite of apparent irregularities in thickness of the sides and bottoms.

Hour-to-hour.-For the hour-to-hour studies a more precise method was used, as the volumes being measured were often small. The universal containers were replaced by glass jars of similar size and shape whose sides and bottoms were very regular in thickness. Their capacity was such that the height of the column of sputum could be measured in millimetres and converted to millilitres by dividing by two. The sputum was first liquefied by adding a known volume of sodium hypochlorite (approximately $3 \%$ ) and shaking. Ten subjects took part in the hour-to-hour section, four of whom had previously taken part in the main study. They were awakened at 5 a.m. on the first morning, and sputum containers were changed every hour of the day and night, whether they had been used or not, for the next seven days. Co-operation of the patients was high and we certainly collected most of the sputum expectorated.

It was emphasized to the subjects that saliva should be excluded as far as possible, and the saliva content of the sputum was generally very small. In the one-hour and half-hour series its presence in small amounts was ignored, while in the hourto-hour series a few specimens which appeared to consist entirely of saliva were recorded as zero. 


\section{Results in One-hour and Half-hour Series}

The means and standard deviations of the 24-hour volumes in the one-hour and half-hour series did not differ significantly, and they can be considered together. Most of our subjects produced large daily sputum volumes, and column 2 of Tables II and III shows the number of subjects in the different 24-hour volume groupings.

Fig. 1 shows the mean and range of the daily readings of onehour volume, 24-hour volume, and one-hour percentage for each subject in the one-hour series, arranged in ascending order of mean 24-hour volume. Fig. 2 gives the same information for the half-hour series.

A large day-to-day variation in the three indices is seen in the wide range shown by most subjects on either side of each mean. This was quite a striking finding, which occurred irregularly and was not attended by any apparent change in the subject's clinical condition.

In view of these wide fluctuations an analysis of variance was carried out on the figures for one-hour and half-hour volume, one-hour and half-hour percentage, and 24-hour volume. The results are shown in Table I. In each case the difference between men was significantly greater $(P<0.001)$ than the variation from day-to-day within men. The 24-hour volume was the best index ( $F$ ratio 16.9) for differentiating between men, closely followed by the one-hour volume ( $F$ ratio 16.3). (The $F$ ratio is an index comparing variability between subjects to variability within subjects, and the higher the index the more the test discriminates between subjects.) The 24hour volume also had the lowest coefficient of variation. As the 24-hour volumes were of similar mean and S.D., only that from the one-hour series is quoted. It is of interest that the
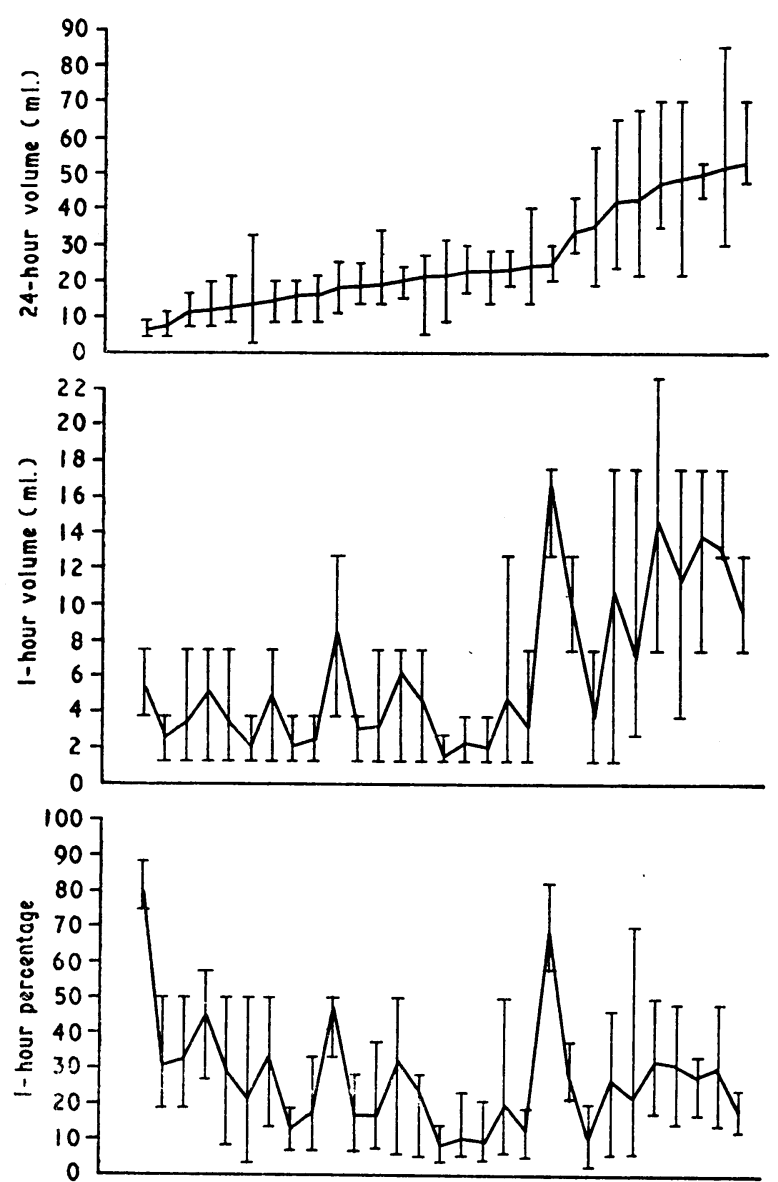

Fig. 1.-Mean 24-hour volume, one-hour volume, and onehour percentage for all subjects in the one-hour series. jects are arranged from left to right in ascending order of mean mean half-hour volume is nearly as large as the mean one-hour volume and the S.D.s are very similar, suggesting that most of the one-hour sputum is in fact brought up in the first halfhour. However, the $\mathrm{F}$ ratio of the half-hour volume is much lower and it is thus a poorer discriminating test.
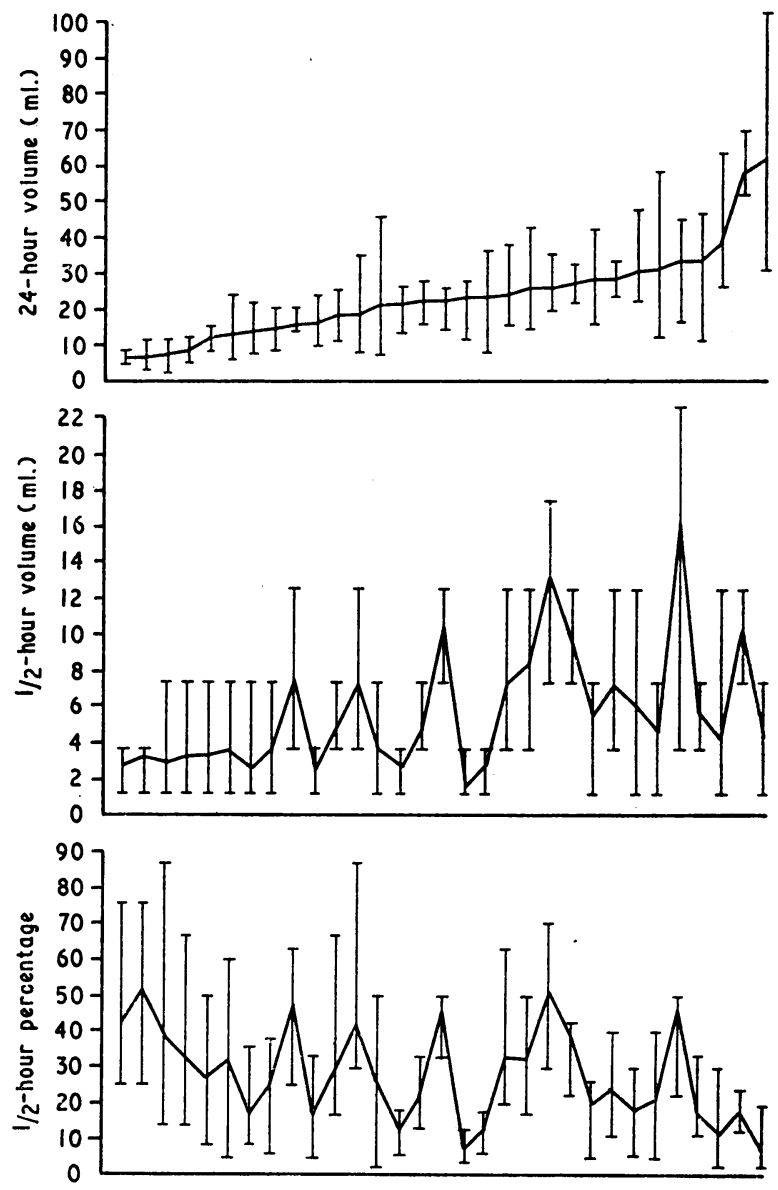

FIG. 2.-Results of the half-hour series arranged in the same way as in Fig. 1 .

TABLE I

\begin{tabular}{|c|c|c|c|c|}
\hline & Mean & S.D. & $\begin{array}{l}\text { Coeff. of } \\
\text { Variation }\end{array}$ & F Ratio \\
\hline $\begin{array}{l}\text { One-hour volume } \\
\text { One-hour percentage } \\
\text { 24-hour volume } \\
\text { Half-hour volume } \\
\text { Half-hour percentage }\end{array}$ & $\begin{array}{l}6.3 \mathrm{ml} . \\
26.9 \% \\
25.8 \mathrm{ml} . \\
5.7 \mathrm{ml} . \\
27.6 \%\end{array}$ & $\begin{array}{r}2 \cdot 9 \\
11 \cdot 4 \\
9 \cdot 3 \\
2 \cdot 7 \\
13 \cdot 7\end{array}$ & $\begin{array}{l}46 \cdot 1 \\
42 \cdot 3 \\
35 \cdot 9 \\
48 \cdot 0 \\
49 \cdot 7\end{array}$ & $\begin{array}{r}16 \cdot 3 \\
14 \cdot 5 \\
16 \cdot 9 \\
11 \cdot 1 \\
6 \cdot 5\end{array}$ \\
\hline
\end{tabular}

In spite of these variations, when subjects are grouped according to mean 24-hour volume, as in Table II, the average one-hour percentage is remarkably constant for the groups from $10 \mathrm{ml}$. upwards, varying only from $19 \%$ to $25 \%$ for a 24 -hour volume range from $10 \mathrm{ml}$. to over $50 \mathrm{ml}$.

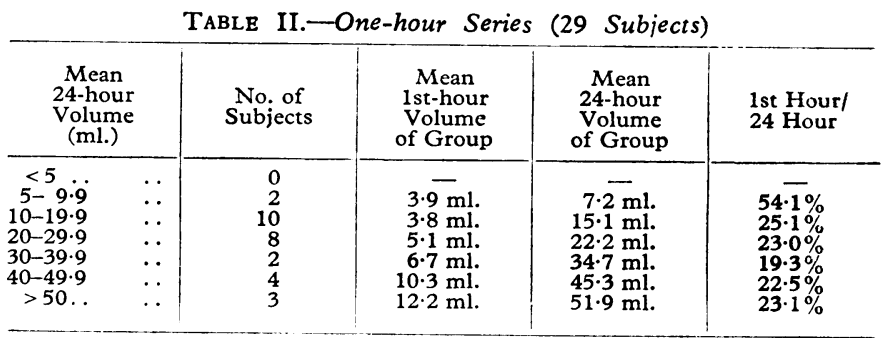

Table III shows the data from the half-hour series arranged in the same way, and again, excluding the 5-9.9 $\mathrm{ml}$. group, the average group percentages are fairly close together, except 
perhaps for the $>50 \mathrm{ml}$. group. In both tables the average of the $5-9.9 \mathrm{ml}$. group is considerably greater than the rest. The reason for this is not clear. The numbers are small and it could partly be the way the volumes were recorded. Further studies are needed on subjects with lower 24-hour volumes.

TABLE III.-Half-hour Series (31 Subjects)

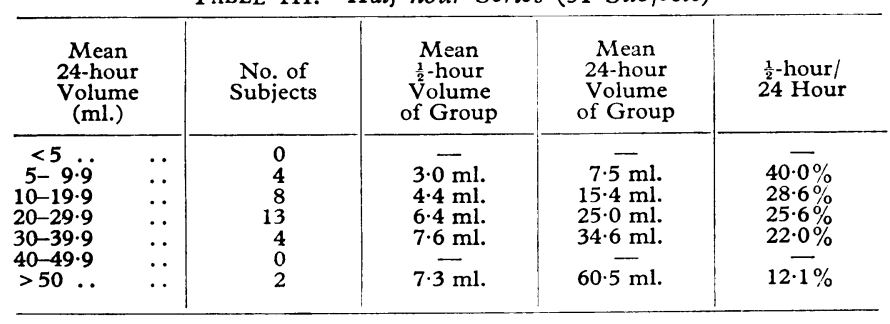

\section{Results in Hour-to-Hour Series}

The results of the hour-to-hour series of measurements are shown in Fig. 3. Each column of the histogram represents the mean of 70 measurements in 10 patients. There is the expected peak in the early morning, followed by a decline until mid-afternoon, when there is another sharper peak. A third peak in the late evening is followed by very low levels during the night. Some patients produced sputum intermittently throughout the night, while others apparently slept soundly. The reasons for the various peaks in sputum production are uncertain. Fig. 3 shows that some meals or hot drinks are followed by a rise in production, but this rise varies considerably from meal to meal. Smoking probably plays a part, since smoking was officially permitted only after meals, and a great many patients have remarked that they find it easier to "break the phlegm" after an early morning cup of tea and cigarette. In this series, however, its effects are hard to determine, as surreptitious smoking or even open flouting of the smoking rules occurred on occasion.

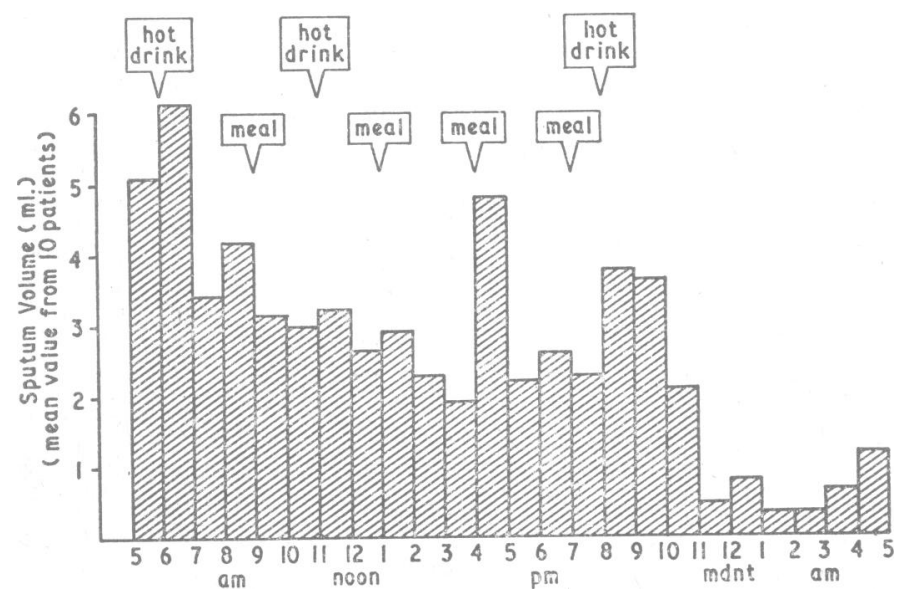

FIG. 3.- Mean volume of sputum expectorated hour by hour by 10 patients, each over seven days.

It will be noticed that in Fig. 3 the 5-6 a.m. sputum forms only a small proportion $(8 \%)$ of that produced in the whole day. The conditions of the experiment were slightly different in the hour-to-hour series compared with the one-hour and half-hour series in that the subjects were not awakened deliberately at 5 a.m. and so the early-morning peak is spread over the hours of roughly 5-7 a.m., the combined amounts for these hours amounting to $17.7 \%$ of the total.

\section{Discussion}

The striking day-to-day variation which occurred in the subjects' early-morning volume, 24-hour volume, and earlymorning percentage was rather unexpected, since it had been assumed that in the absence of gross infection and in the relatively stable atmospheric conditions of the ward there would be little variation. The cause may lie in several factors. Errors of collection might possibly play a part, since if a subject awoke before 5 a.m. any sputum he expectorated would be added to his previous day's total and not to his one-hour or half-hour volume. In the hour-to-hour studies, however, very little sputum is expectorated before 5 a.m., certainly not enough to account for the variations found. Losses from swallowing of sputum and accidental losses were probably small, as co-operation in the group was very high.

The observed variations probably reflect actual changes in the rate of bronchial secretion during the day and from day to day, but the causes for this variation are not yet known. Environmental factors such as temperature and humidity seem unimportant in this group because the subjects did not vary in unison. Tobacco smoking probably is not a very important factor in these subjects, since a majority of them smoked cigarettes and there does not seem to be any striking difference in the daily variations between those smoking and those who did not. In Fig. 1 the subjects who did not smoke at the time of the investigation are, from left to right, Nos. 6, 9, 10, 11, 13, 14, 15, and 23 . In Fig. 2 they are Nos. 1, 8, 9, 11, 17, 26, 27 , and 31 .

\section{Summary and Conclusions}

In this hospital group of cases of chronic bronchitis recovering from acute episodes, sputum expectorated during the first hour of the day, between 5 and 6 a.m., averaged about a quarter of the volume produced during the whole 24 hours, and this average was fairly well maintained over a wide range of 24hour volumes, except for patients producing less than $10 \mathrm{ml}$. in 24 hours. The ratio shows marked variations from day to day and from patient to patient, and it is suggested that these represent real variations in secretion due to unknown causes. The variability of the 24-hour volume was less than that of the first hour and first half-hour volumes. The volume produced in the first half-hour was almost as great as that produced during the first hour. As a means of differentiating between one man and another there is little to choose between the 24hour volume and the first-hour volume. However, because of the large day-to-day variation, the significance of a single measurement of first-hour sputum volume must be interpreted with caution in assessing an individual patient.

Volumes expectorated decline throughout the day with the exception of certain peaks which may be related to the consumption of hot drinks.

Much more work remains to be done to elucidate the factors influencing secretion and expectoration of sputum, which has been surprisingly little studied quantitatively.

My thanks are due to Dr. J. C. Gilson for much helpful criticism and encouragement, to Dr. J. D. Ball for allowing me to study patients under his care, to Mr. C. E. Rossiter for his valuable statistical advice, and to Sister $\mathrm{D}$. Tristram and her staff for their generous assistance.

\section{REFERENCES}

Elmes, P. C., Dutton, A. A. C., and Fletcher, C. M. (1959). Lancet, 1,

Fletcher, C. M., Elmes, P. C., Fairbairn, A. S., and Wood, C. H. (1959). Brit. med. Ұ., 2, 257. 